\title{
The Value of Perioperative ECG Recordings in the Cardiovascular Monitoring and Risk Assessment of Asymptomatic Patients with Total Hip Arthroplasty
} \author{
Gergely ${ }^{4}$ \\ 1. Department of Internal Medicine IV, University of Medicine and Pharmacy of Tirgu Mures, Romania \\ 2. University of Medicine and Pharmacy of Tirgu Mures, Romania \\ 3. Clinic of Orthopedics and Traumatology, Clinical County Hospital Mures, Tirgu Mures, Romania \\ 4. Department of Orthopedics I, University of Medicine and Pharmacy of Tirgu Mures, Romania
}

Attila Frigy¹, István Szabó-Györke²*, Krisztina Csomor², András Czédula³, Sándor-György Zuh4, István

\begin{abstract}
Aim: To evaluate the value of a more closed perioperative ECG follow-up in the investigation and forecasting of cardiovascular events during and after hospital admission. Methods: We included in the study 30 asymptomatic patients from cardiac point of view (14 women, 16 men, mean age 63 years), who underwent total hip arthroplasty. ECGs were performed on the day before surgery, on the day of surgery, after the intervention, and on the 3rd day. We looked for the correlations between ECG changes and clinical events. Results: The commonest postoperative new ECG changes were QTc prolongation (14 patients - 46,6\%) and sinus tachycardia (8 patients - 26,6\%). There were no major cardiac events during hospitalization, and we found possible correlations in two cases between perioperative ST-T changes and postdischarge clinical events: one exitus and one case of ischemic heart disease. Conclusions: Our data do not support the efficacy of a more closed, routine ECG follow-up in the studied, low risk patient population, but new perioperative ST-T changes always have to be taken into account.
\end{abstract}

Keywords: electrocardiogram, total hip arthroplasty, risk evaluation

Received 12 March 2018 / Accepted 25 May 2018

\section{Introduction}

Elective total hip arthroplasty (THA) is a widely performed intermediate-risk orthopedic intervention with multiple cardiovascular effects and possible clinical consequences. THA is one of the most common elective orthopedic procedures, its frequency is continuously increasing in Romania, primarily due to the spreading of degenerative joint diseases and ageing of population [1].

There is a wide range of potential cardiovascular complications associated with the procedure, mainly due to the stress response, the main consequence being the increased oxygen demand of the myocardium and the imbalance between prothrombotic and fibrinolytic factors. At the same time, other parameters like type of the anesthesia, surgical technique, duration and quantity of bleeding and body temperature during the intervention could have impact [2, $3]$.

This relatively frequent surgical operation has a 30-day and 90 -day mortality rate of $0.30 \%$ and $0.65 \%$, respectively. The most important risk factors for early mortality are male gender, age and the occurrence of cardiovascular complications (myocardial infarction, pulmonary embolism) [2-4]. Comorbid heart diseases also complicate the postoperative period by further decreasing quality of life and general disposition [5].

In our study, we investigated the value of sequential ECG recordings performed in the perioperative period in the prediction of early or late cardiovascular events occurring after THA, in a low risk population.

\section{Methods}

Between June and December 2016, 30 cases (14 females, 16 males; average age: 63 years) undergoing THA were selected prospectively and randomly from the patients of the Orthopedic and Traumatology Clinic of the Clinical County Hospital Mures. All the patients voluntarily agreed to participate in the study, signing an informed consent. Inclusion criteria were the lack of known heart disease and the absence of cardiac symptoms (typical cardiac complaints). Prior to hospitalization, all patients had a preoperative cardiac examination, which did not identify cardiac abnormalities. The study was performed with the approval of the Scientific Ethical Committee of the Clinical County Hospital Mures.

For each patient, three standard 12-lead electrocardiograms were recorded: the first, on the day before surgery, the second, right after surgery and the third, three days after surgery. The ECGs were recorded under basal circumstances: no eating, drinking coffee and smoking at least for 2 hours before, in supine position. The places of the chest electrodes were marked during the first registration, for interpreting correctly any ECG-changes on the consecutive ECG-recordings.

The following characteristics of the patients were registered: gender, age, body weight, body height, waist circumference, family history, tobacco, coffee and alcohol 
consumption, possible cardiac complaints in the previous month. During the ECG analysis, we assessed the following parameters and their changes: rhythm, QRS axis, heart rate, bundle branch block pattern, Sokolow-Lyon index, low voltage pattern, ST-T changes (ST depression, -elevation, negative $\mathrm{T}$ waves), arrhythmias, $\mathrm{QT}$ interval (corrected QT - QTc - using the Bazett's formula). We used a cut-off value of $440 \mathrm{~ms}$ for assessing the tendency for QTc prolongation. Each recording was evaluated by two independent readers, and the parameters were recalculated in the cases when mismatch was present. Special attention was paid to the three ECG parameters which predict best the potential cardiac events: heart rate, ST-T changes and QTc prolongation.

By telephone follow-up, at one and three months after hospital discharge, the status of the patients was assessed prospectively. New and significant cardiovascular complaints, antalgic medication need, emergency hospital admissions and mortality (cardiovascular and general) were recorded.

The statistical evaluation of heart rate and QTc interval was done by paired t-test and repeated measurement analysis of variance (ANOVA) with a significance level set at $\mathrm{p}<0.05$.

\section{Results}

The dynamics of the ECG curves, the incidence of diverse changes (compared to the preoperative ECG), is presented in Table 1. The most common change was the prolongation of the QT interval. It should be noted that most of the changes which appeared on the second ECG curve (immediately after surgery) persisted on the third ECG curve as well.

Table 2 shows changes in heart rate and QTc interval in relation to surgery. Significant increase in frequency and prolongation of QTc were clearly detectable immediately after surgery. On the $3^{\text {rd }}$ day after surgery the decrease in heart rate was not found to be significant, while the QTc interval shortening proved to be significant, even though it did not return to the initial values ( $\mathrm{p}=0.0176)$.
During telephone follow-ups, we encountered two cases whose output had a possible correlation with the changes in the perioperative ECGs. The first one was a 68-year-old non-alcoholic and non-smoking female patient with a BMI of $32 \mathrm{~kg} / \mathrm{m}^{2}$, who had been diagnosed with ischemic heart disease (typical chest pain) associated with ECG abnormalities. This patient showed on the preoperative ECG, in the leads $\mathrm{V} 1-\mathrm{V} 4$, negative $\mathrm{T}$ waves which were extending to the V5 lead on the second ECG (right after surgery), the final ECG curve indicating them again only in V1-V4.

The second case is a 76-year-old female patient with a BMI of $29 \mathrm{~kg} / \mathrm{m}^{2}$, occasionally drinking alcohol, not smoking. She had mild, intermittant symptoms during the month prior to surgery - palpitations, non-typical chest discomfort, dizziness. Acute myocardial infarction and death was recorded during the telephone follow-up. In this patient we found negative $T$ waves on the preoperative ECG, in the leads V1-V3, which became more extended on the first postoperative day (leads V1-V6), being present in the leads V1-V5 on the $3^{\text {rd }}$ postoperative day (Figures 1 and 2). The patient was completely asymptomatic during the perioperative period and the ECG changes were attributed to anemia. In both cases, the QTc interval was in the normal range on all ECGs.

\section{Discussion}

Preoperative cardiovascular risk assessment is a complex and compulsory part of any planned surgical procedure, having the aim to identify high-risk patients. For some of these, surgery (temporarily) cannot be performed, further investigation or specific treatment being required. Cardiac risk assessment is based on a thorough clinical examination (history, physical examination) and on the classical 12-lead ECG. The algorithms of the different guidelines published by various associations describe the tasks in detail and take into account the risk level of the operation and its lifesaving or urgent nature in addition to the patient's characteristics (clinical findings, diagnoses, functional capacity, biomarkers, drugs used, etc.) $[6,7]$.

Table 1. The occurrence of new ECG changes related to the first (preoperative) ECG recording. The 3rd column refers to the cases with the changes present on both the 2nd and 3rd ECGs. *only in one case occured new negative T waves, in the other cases negative T waves (more limited) were already present on the first ECG

\begin{tabular}{lcc}
\hline ECG change & 2. ECG & 3. ECG \\
\hline QT prolongation (QTc $>440 \mathrm{~ms})$ & 12 & 8 \\
Tachycardia (>90 beats/min) & 7 & 5 \\
New or increasing (extending) negative T waves in the precordial leads ${ }^{*}$ & 3 & 4 \\
Normalization of negative T waves in the precordial leads & 1 & 2 \\
\hline
\end{tabular}

Table 2. The values of heart rate and QTc interval (mean \pm standard deviation) resulted from the three ECG recordings; $p$ values resulted from comparisons $\left({ }^{*}=\right.$ significant change)

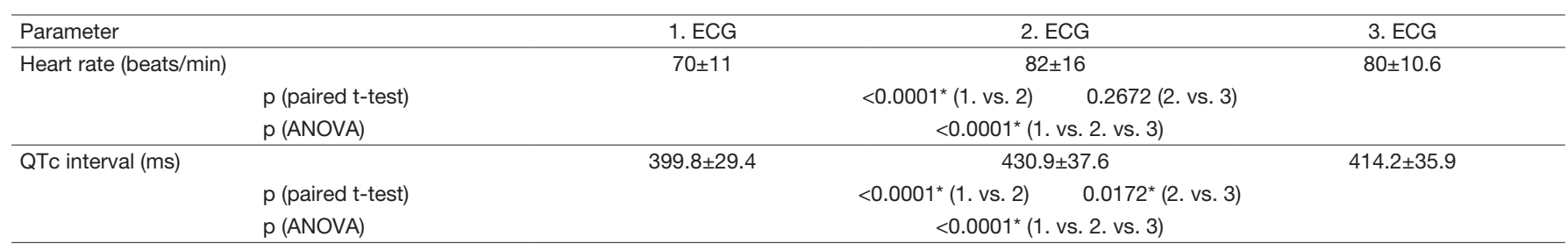




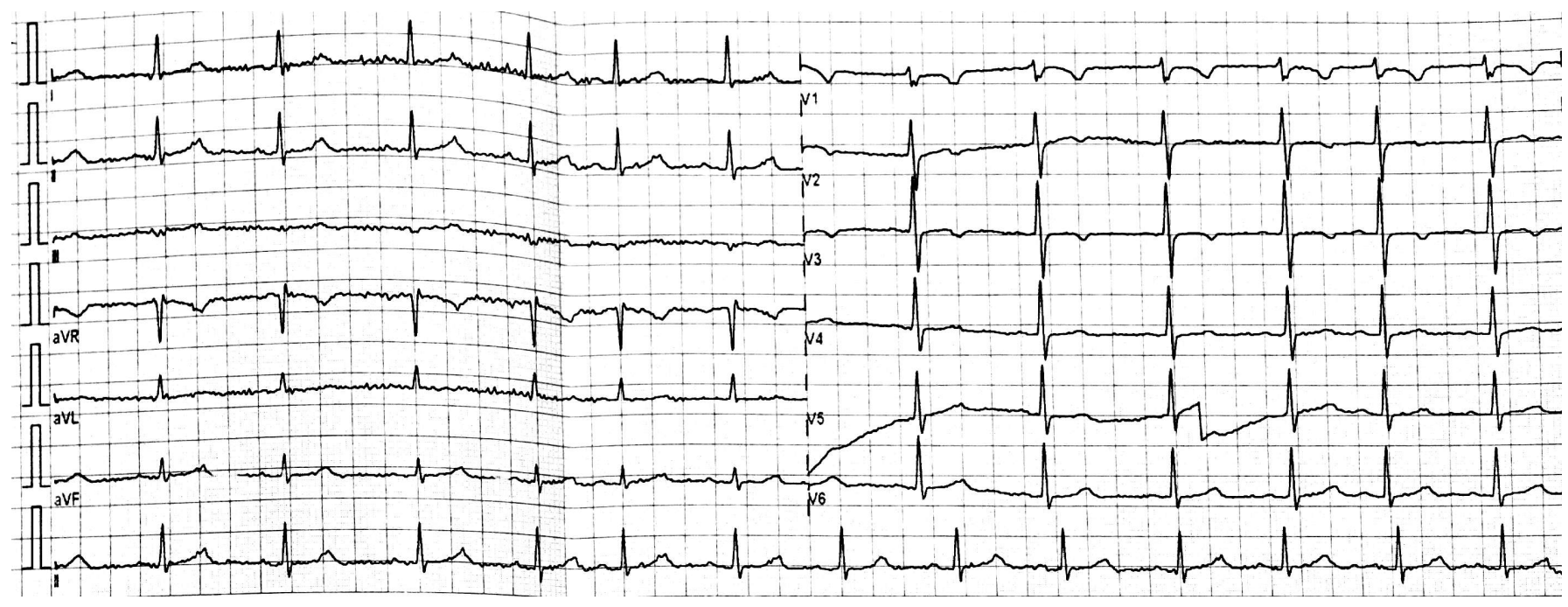

Fig. 1. The preoperative ECG recording of the 76 years old women who suffered myocardial infarction and died postoperatively: negative T waves in the V1-3 leads

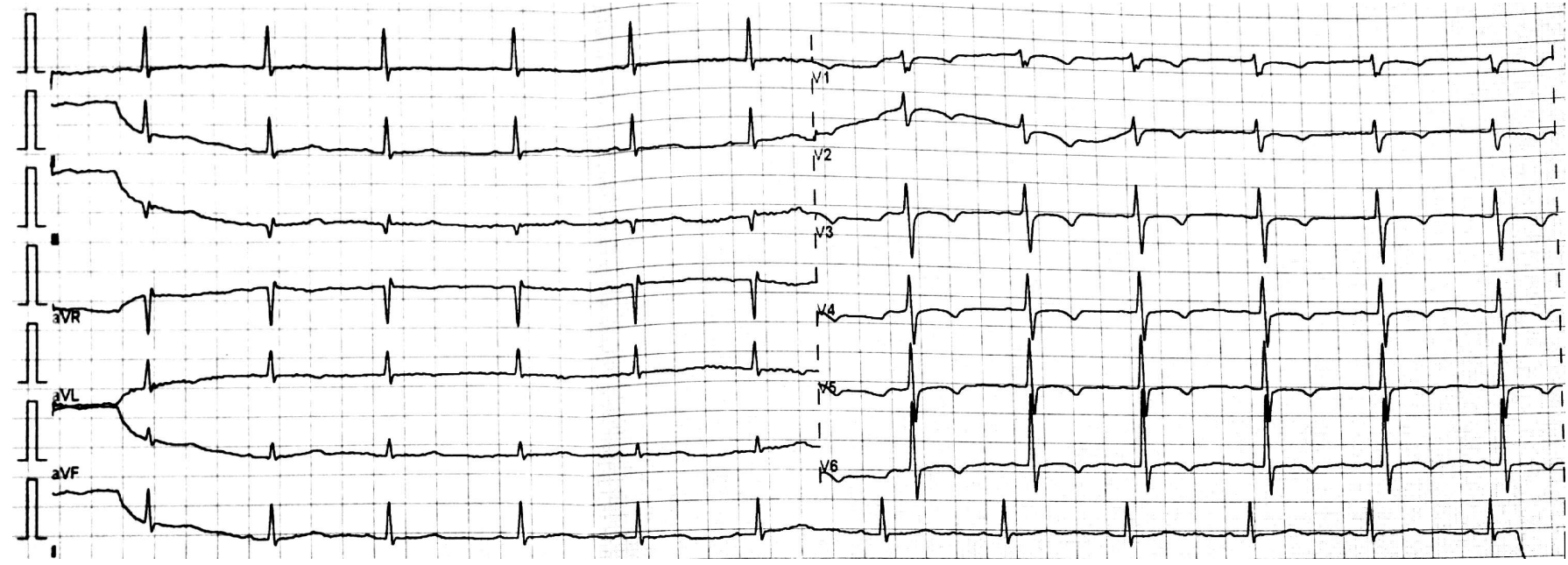

Fig. 2. ECG recording of the same patient at 3 hours after surgery: more extended negative $T$ waves heralding myocardial ischemia

Despite careful preoperative assessment and screening, intrahospital or postdischarge cardiovascular events, especially myocardial infarction and pulmonary embolism, may cause the death of the patient. Peri- and postoperative follow-up and risk assessment is therefore a major practical issue, its implementation being currently less standardized. Primarily, in the case of asymptomatic patients without known cardiac disease, it is a challenge to find out the tools which are the most proper for an effective perioperative risk assessment.

In our work, low risk patients without known cardiac involvement were studied in the perioperative period using standard ECG recordings, in the setting of a relatively frequent, intermediate-risk orthopedic intervention. Our goal was to screen and find out postoperative cardiac events and to do risk assessment with a simple, inexpensive and easily accessible diagnostic tool.

The dynamics of heart rate and QTc interval in the postoperative period (significant increase and prolongation) clearly indicate the operation-induced stress response. The reasons for this are multiple - mental factors (anxiety), blood loss, pain, effects of certain drugs, etc. - and its es- sence is the enhanced sympathetic tone, which is a known etiopathogenetic factor in triggering cardiovascular events [8]. Surprisingly, we found frequently QTc prolongation exceeding $440 \mathrm{~ms}$, but this did not coincide with the appearance of symptomatic arrhythmias.

New or increasing ST-T changes suggesting myocardial ischemia or right ventricular overload were rarely present, and only in one patient the repolarization changes being not present in the preoperative period. However, the two patients with cardiac events in the postoperative period took part from this group, the clinical significance of the new or increasing ST-T changes, looking retrospectively, being unquestionable. The relatively low incidence of relevant ST-T changes, together with the low peri- and postoperative clinical events number are the main limitations of our study, which could be considered as a pilot type in this context.

Periodic and postoperative risk assessment is an important and complex task in the case of intermediate and high-risk surgical interventions. Although, there is no optimal method available currently, it is likely that this will be based on a combination of multiple parameters. In this 
regard, more and more data are available about the value of biomarkers - NT-proBNP, troponin - and different score systems [9-12] in this setting. In the prevention of clinical events, however, remains of primary importance the onsite availability of the adequate postoperative care [13].

\section{Conclusions}

Based on our data, in a population with low cardiovascular risk, the value of perioperative risk assessment using a closer ECG follow-up is questionable, mainly due to the relatively small number of peri(post)operative clinical events. At the same time, the complex stress reaction caused by surgery can be perceived as a cardiac stress test equivalent, and, in this context, perioperative ST-T changes always have to be taken into account. On the other hand, in the case of preoperative repolarization anomalies, the new or increasing ST-T changes on the postoperative (mandatory) ECG could indicate myocardial ischemia and an increased risk, despite of the existence of a negative preoperative routine cardiac evaluation. Also, our data support the need for a more thorough cardiovascular evaluation of asymptomatic patients with non-specific ECG changes prior to surgery.

\section{Disclosures}

The authors have no financial interests in writing this article.

\section{References}

1. Chiriac ND, Minca DG. An analysis of variations in practice regarding hip arthroplasty in elderly people, using clinical and admnistrative data of hospitals. [O analiză a variațiilor de practică privind artroplastia șoldului la pacienții vârstnici, utilizând datele clinice și administrative ale spitalelor.] Acta Medica Transilvanica. 2010; 2: 56-58.

2. Basilico FC, Sweeney G, Losina E, et al. Risk factors for cardiovascular complications following total joint replacement surgery. Arthritis Rheum. 2014; 58: 1915-1920.

3. Lu N, Misra D, Neogi T, et al. Total joint arthroplasty and the risk of myocardial infarction: a general population, propensity score-matched cohort study. Arthritis Rheumatol. 2015; 67: 2771-2779.

4. Berstock JR, Beswick AD, Lenguerrand E, et al. Mortality after total hip replacement surgery. Bone Joint Res. 2014; 3: 175-182.

5. Király E, Gondos T. The role of cardiovascular diseases in the development of disease perception after hip endoprosthesis implantation. [Cardiovascularis betegségek szerepe csípőízületi endoprotézis beültetése utáni betegségérzet kialakulásában.] Orv Hetil. 2011; 152: 464-468. [Hungarian]

6. Kristensen SD, Knuuti J, Saraste A, et al. 2014 ESC/ESA Guidelines on non-cardiac surgery: cardiovascular assessment and management. Eur Heart J. 2014; 35: 2383-2431.

7. Fleisher LA, Fleischmann KE, Auerbach AD, et al. 2014 ACC/AHA guideline on perioperative cardiovascular evaluation and management of patients undergoing noncardiac surgery. J Am Coll Cardiol. 2014; 64: e77-e137.

8. Shen MJ, Zipes DP. Role of the autonomic nervous system in modulating cardiac arrhythmias. Circ Res. 2014; 114: 1004-1021.

9. Rodseth RN, Biccard BM, Le Manach $\mathrm{Y}$, et al. The prognostic value of pre-operative and post-operative B-type natriuretic peptides in patients undergoing noncardiac surgery: B-type natriuretic Peptide and $\mathrm{N}$-terminal fragment of pro-B-type natriuretic Peptide: a systematic review and individual patient data meta-analysis. J Am Coll Cardiol. 2014; 63: 170-180.

10. Devereaux PJ, Chan MT, Alonso-Coello P, et al. Association between post-operative troponin levels and 30-day mortality among patients undergoing noncardiac surgery. JAMA. 2012; 307: 2295-2304.

11. Haynes AB, Regenbogen SE, Weiser TG, Lipsitz SR, et al. Surgical outcome measurement for a global patient population: validation of the Surgical Apgar Score in 8 countries. Surgery. 2011; 149: 519-524.

12. Lee TH, Marcantonio ER, Mangione CM, Thomas EJ, et al. Derivation and prospective validation of a simple index for prediction of cardiac risk of major noncardiac surgery. Circulation. 1999; 100: 1043-1049.

13. Ausset S, Auroy $\mathrm{Y}$, Verret C, et al. Quality of postoperative care after major orthopedic surgery is correlated with both long-term cardiovascular outcome and troponin Ic elevation. Anesthesiology. 2010; 113: 529-540. 